\title{
Strengthening Science and Technology for Health Research: Perspectives from Trade, Development, and Innovation
}

\author{
Paul Ernest N. de Leon, ${ }^{1}$ Reneepearl Kim P. Sales, ${ }^{2}$ Lester Sam A. Geroy ${ }^{2}$ and Jaifred Christian F. Lopez ${ }^{2}$ \\ ${ }^{1}$ Philippine Council for Health Research and Development, Taguig City, Philippines \\ ${ }_{2}^{2}$ Alliance for Improving Health Outcomes, Inc., Quezon City, Philippines
}

\begin{abstract}
Background. It has long been observed globally that the extent to which developing countries can achieve health targets depends on their capacity to generate, harness, and apply science and technology (S\&T). Beyond the health sector, S\&T contributes to development by providing a solid foundation for education, infrastructure, and economic progress. The United Nations Conference on Trade and Development (UNCTAD) suggests a set of fundamental elements for an ideal S\&T environment: knowledge generators, producers, infrastructures, and the policy instruments.

Objectives and Methods. Through document and secondary data review guided by the UNCTAD fundamental elements, this paper aimed to 1) provide an overview of the S\&T policies in the country, 2) assess the country's S\&T status, 3) identify gaps and challenges, and 4) provide recommendations to strengthen the S\&T environment in the country.
\end{abstract}

Results. The country's set of policies in S\&T has succeeded in attracting businesses, nurturing good governance, and applying necessary regulatory mechanisms that offers protection and incentives to innovation. While performance in Education \& Research has improved, spending on research, patent applications, and journal publications lags regionally and globally. The country's university-industry collaboration has been in decline since 2015. Between 2013 to 2015 , innovations strongly enabled changes in business and organizational models. Data show that the country has been devoting increasing percentage of its GDP to Gross Capital Formation. Conversely, logistics performance has been decreasing. The country's score for information and communication technology has been increasing since 2013. Since 2014, the density of newly registered business has remained stagnant.

Conclusion. Policies implemented through the years in the Philippines have managed to balance strengthening infrastructure capacity while increasing translation and uptake of new knowledge and technologies by enterprises. The country's S\&T performance has remained largely stagnant despite the availability of human capital. The Philippines has devoted low funding to research and development, indicating the low priority that it has for S\&T. This is manifested in the low research output of the country, in the form of patents and publications, that lags both regionally and globally. The availability of quality infrastructure is a requirement for efficient work of researchers and facilitates adaption of new technologies by enterprises. However, these developments must be coupled with good logistical processes to meet the demands of researchers and the industry.

Key Words: technology, science, health policy, research

\section{INTRODUCTION}

It has long been observed globally that the extent to which developing countries can achieve intended national and international health targets depends on their capacity to

Corresponding author: Reneepearl Kim P. Sales, RMT, MLS(ASCPi)CM, MSc

Alliance for Improving Health Outcomes

62 West Avenue, Quezon City 1104, Philippines

Email: kimsales@aiho.org.ph generate, harness, and apply science and technology (S\&T). ${ }^{1}$ Beyond the health sector, S\&T contributes to development by providing a solid foundation for education, infrastructure, and economic progress. As such, countries have interest in 
reinforcing science and technology through innovation, dissemination, adaptation, implementation, and utilization. ${ }^{2}$

In the health sector, the discovery and application of new technologies has led to an expansion of options to solve public health problems in the form of recombinant vaccines, molecular diagnostics, and recombinant therapeutic proteins, among others. ${ }^{3}$ However, developing countries continue to face challenges in S\&T. In an indicative assessment of research and development (R\&D) capability and capacity, only a few developing countries possess the necessary skills to engage in scientific research. Some developing countries have research capability but fail in the next step of research translation due to poor industrial production base. ${ }^{4}$ In another survey, results showed that countries with high burden of diseases are underrepresented in and do not make significant contribution to the global pool of health and health-related publications. ${ }^{5}$ A capacity assessment conducted by the Council on Health Research for Development (COHRED) found that research groups in developing countries are "small, vulnerable, under-funded, and deficient in basic equipment and trained researchers and support staff." ${ }^{\prime}$ As these countries continue to lag in S\&T, creative application of the sciences fails and the current disparity with industrialized nations widens. ${ }^{7}$

For the S\&T sector to have a continued contribution and impact on health, countries need a clear understanding of their current capacities, strengths, and weaknesses. The United Nations Conference on Trade and Development (UNCTAD) suggests a set of fundamental elements for an ideal S\&T environment (Figure 1). ${ }^{8}$ The management of an S\&T environment needs to consider its knowledge

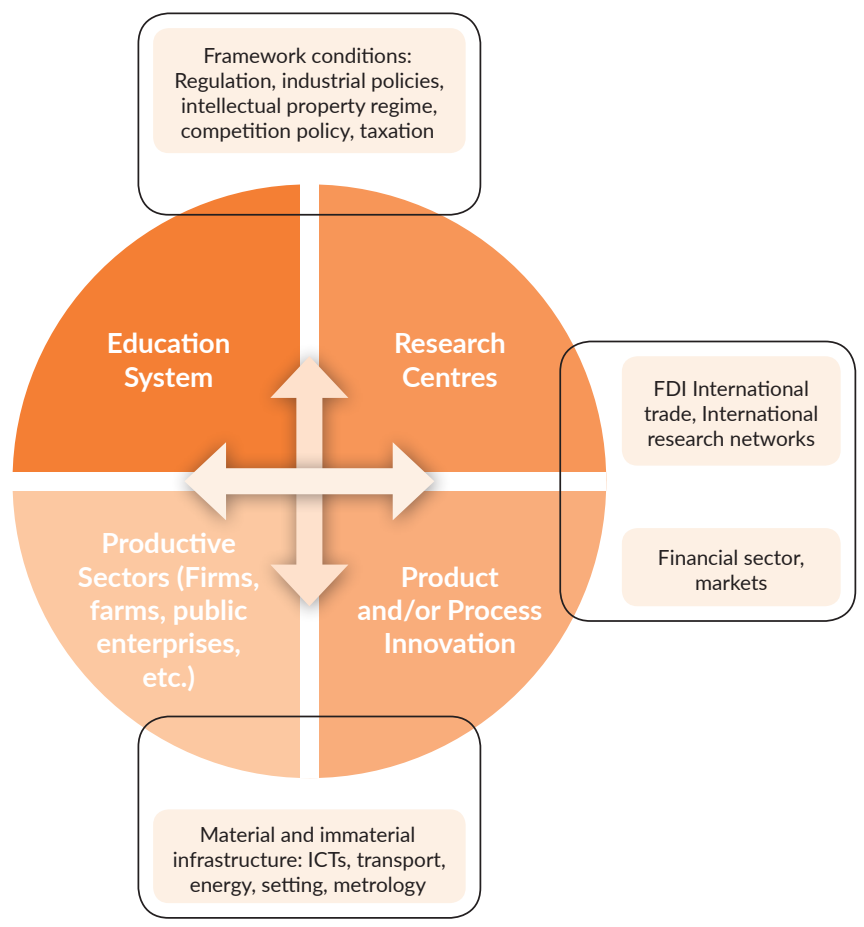

Figure 1. Schematic diagram of a national system of innovation. generators (education and research), producers (firms, farms, and enterprises), infrastructures, and the policy instruments that regulate and enable interactions between the two. It should recognize the role of the financial sector and articulate policies that correct market failures. The S\&T environment should also incentivize collaborations between and among the academe, research centers, and industrial firms both locally and internationally.

Through document and secondary data review guided by the UNCTAD fundamental elements, this paper aimed to 1) provide an overview of the $S \& T$ policies in the country, 2) assess the country's S\&T status, 3) identify gaps and challenges, and 4) provide recommendations to strengthen the $S \& T$ environment in the country.

\section{FRAMEWORK CONDITIONS: HEALTH RESEARCH PRIORITIES AND S\&T POLICIES IN THE PHILIPPINES}

By Executive Order 128, the National Science and Technology Authority was reorganized into the Department of Science and Technology in $1991 .{ }^{9}$ Headed by a Secretary, DOST has been mandated to continue providing the central direction, leadership and coordination of $\mathrm{S} \& \mathrm{~T}$ efforts and the formulation and implementation of policies, plans, programs, and projects for S\&T development. The Department is composed of three sectoral planning councils in charge of 1) formulating policies, plans, programs, projects, and strategies, 2) fund allocation, 3) research and project monitoring, and 4) external fund generation. In addition, seven $R \& D$ institutes are concerned with applied research in the fields of food and nutrition, forest products, metals, textiles, nuclear industry, industrial technology, and advanced sciences. Two collegial bodies are mandated with assistance, recognition, and advisory functions, as well as the role of establishment of international linkages.

Since 2006, the Philippine Council for Health Research and Development has formulated the National Unified Health Research Agenda (NUHRA) every five years. The most recent version, NUHRA 2017-2022, was developed using a bottoms-up approach. The agenda outlines the country's health research priorities for the next five years, taking into consideration the current health status of the country, its capacities, political directions, and international commitments. The NUHRA has six themes: 1) responsive health systems, 2) research to enhance and extend healthy lives, 3) holistic approaches to health and wellness, 4) health resiliency, 5) global competitiveness and innovation in health, and 6) research in equity and health. The creation of a NUHRA is meant to serve as a template to guide public investment in health $R \& D$ towards the goal of a better life for Filipinos.

Since the late 1980s, several policies and strategies have been put in place to develop and improve S\&T in the country. An S\&T Master Plan was formulated by a 
presidential task force in 1988 with the goal of attaining a newly industrialized country status by 2000 . This strategy focused on the modernization of the production sector by mass technological transfer, upgrading of $\mathrm{R} \& \mathrm{D}$ capability, and development of S\&T infrastructure. ${ }^{10}$ One of the products of this strategy was the enactment of Republic Act (RA) 6959 with the objective of accelerating the application and transfer of the benefits of S\&T to the rural areas through the establishment of Provincial Science and Technology Centers. ${ }^{11}$

Pursuing the objective of achieving the status of being a newly industrialized country by 2000 , the Science and Technology Agenda for National Development (or STAND Philippines) outlined the country's development from 1993 to $1998 .{ }^{12}$ STAND identified 13 products and services which had high potential for the world market (export winners), nine products necessary to sustain a productive population (basic domestic needs), and three industries crucial for the development of both export and domestic markets (support industries). Bills enacted during this period were heavily focused on manpower development through providing incentives for inventors, scholarships for S\&T, and streamlining the governance of the Philippine Science High School. ${ }^{13-16}$

Following STAND was the DOST Medium-Term Plan 1999-2004. ${ }^{10}$ This plan envisioned a competent, competitive, and conscientious scientific community through the implementation of six flagship programs: 1) comprehensive program to enhance technology enterprises, 2) integrated program on clean technologies, 3) establishment of a packaging $\mathrm{R} \& \mathrm{D}$ center, 4) expansion of regional metrology centers, 5) S\&T intervention program for the poor, vulnerable, and disabled, and 6) comprehensive S\&T program for Mindanao.

The Medium-Term Philippine Development Plan 2004-2010 included four points to strengthen S\&T in the country: 1) adopting policies focused on making the Philippine National Innovation System work, 2) enhancing competitiveness of $\mathrm{S} \& \mathrm{~T}$ workers, 3) accelerating knowledge creation and transfer, and 4) promoting technology entrepreneurship. ${ }^{17}$ During this period, several S\&T programs were implemented. DOST's technology transfer initiative called Small Enterprise Technology Upgrading Program focused on responding to the technological needs of small and medium enterprises. ${ }^{18}$ The Technology Innovation for Commercialization Program of DOST's Technology Application and Promotion Institute funds and assists $R \& D$ projects to fast track their market readiness and commercial availability. ${ }^{19}$

The basis through which the country's S\&T sector may act upon health research priorities is mainly credited to its policies. A Global Innovation Index (GII) report published by Cornell University, the European Institute of Business Administration (INSEAD), and the World Intellectual Property Organization (WIPO) measured the strength of the Philippine's institutional framework. ${ }^{20}$ Under the Institution pillar, it aimed to assess the quality of a country's policy formulation, regulation, policy implementation, the extent to which the rule of law prevails, and the ease of private entrepreneurship.

Table 1 shows the GII scores of the Philippines from 2013 to 2017 for the Institution pillar and its subpillars: political, regulatory, and business environment. ${ }^{20-24}$ The country's Institution pillar was considered weak in 2013 when it scored 44.8 and ranked 128 out of 142 countries. The report attributed this to low-scoring political stability in the country at the time (32.2 or 130th out of 142 countries). From 2014 to 2017, the country has continually performed better under this pillar, indicating that its set of policies in S\&T has improved in attracting businesses, nurturing good governance, and applying necessary regulatory mechanisms that offer protection and incentives to innovation. A look at disaggregated data also showed improved performance from 2013 to 2017. While scores in the political and regulatory environment subpillars have sometimes declined, the country has risen in global rankings, going from 120 to 84 and 118 to 105 , respectively. The country's business environment was considered a weakness in 2013 but has then significantly improved. It should be noted, however, that disaggregated data under this subpillar revealed that the country is considered weak in terms of the ease of starting a new business, ranking 120 out of 127 countries in 2017.

\section{EDUCATION AND RESEARCH}

The level and standard of education and research activity in a country are considered prime determinants of its S\&T capacity. Figure 2 shows the Philippine GII scores for Human Capital and Research from 2013 to $2017 .^{20-24}$ While the country has been improving overall, the Education subpillar has been weak since 2013. Between 2013 and 2017, the country has allocated less than 3\% of its Gross Domestic Product (GDP) on education per year. Meanwhile, the country's strength in Tertiary

Table 1. Philippines institution scores (2013-2017)

\begin{tabular}{|c|c|c|c|c|c|}
\hline & 2013 & 2014 & 2015 & 2016 & 2017 \\
\hline Institutions & $44.8^{*}$ & 49.6 & 51.8 & 53.4 & 52 \\
\hline Political environment & 42.5 & 45.7 & 40.5 & 44.9 & 44.2 \\
\hline Regulatory environment & 49.5 & 50.1 & 51.3 & 51.6 & 48.4 \\
\hline Business environment & $42.6^{*}$ & 53 & 63.5 & 63.9 & 63.3 \\
\hline
\end{tabular}

\footnotetext{
* Indicates a weakness
} 


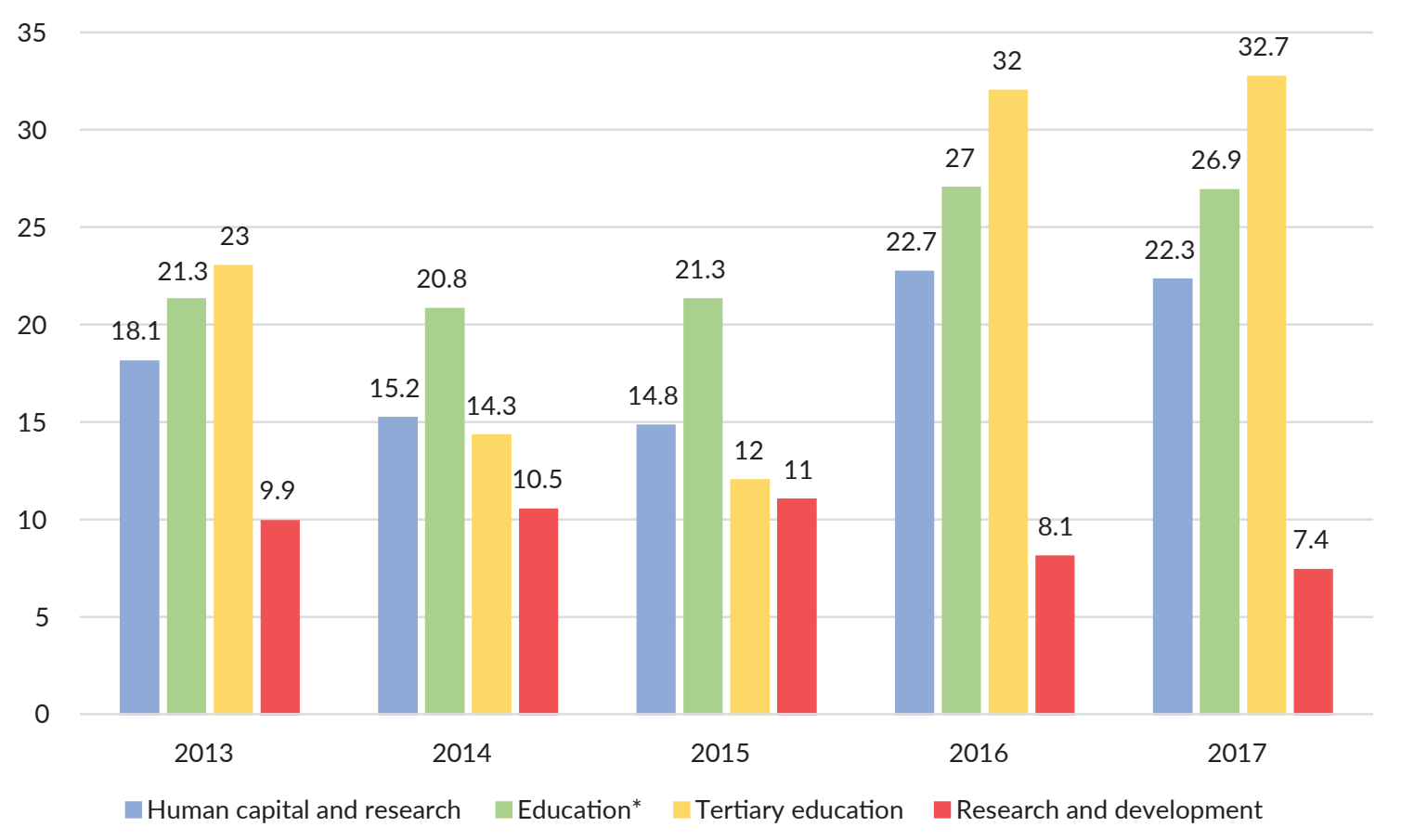

*Indicates a weakness

Figure 2. Philippines GII Human Capital and Research Pillar and Subpillar Scores (2013-2017).

Education stems from its consistently high numbers of graduates in science and engineering courses. In 2017, the Philippines ranked 27th globally and third compared with its neighboring countries in graduates in science and engineering as percentage of total tertiary graduates.

While not considered a weakness, performance in the Research and Development subpillar has been decreasing (Figure 2). ${ }^{20-24}$ Between 2015 and 2016, the number of full time-equivalent (FTE) researchers increased by almost $200 \%$, going from 78.3 to $221.3 \mathrm{FTE}$ researchers per million population. This dropped in 2017 to $189.4 \mathrm{FTE}$ researchers per million population (Figure 3 ).

In terms of spending (Table 2), the country's Gross Expenditure on R\&D (GERD) as percent of its GDP since 2013 has been $0.1 \%$, lagging behind its neighbors Singapore (2.2\%), Malaysia (1.3\%), and Thailand (0.6\%) in 2017. It should be noted that R\&D spending by businesses as \% of total GERD was strong between 2013 and 2015. However, this has dropped by almost 50\% since 2016. A similar trend is observed for R\&D financed by foreign investment, which decreased by over $50 \%$ between 2015 and 2016 .

Table 3 shows the research output by researchers as a result of inventions and innovations from 2013 to 2017.20-24

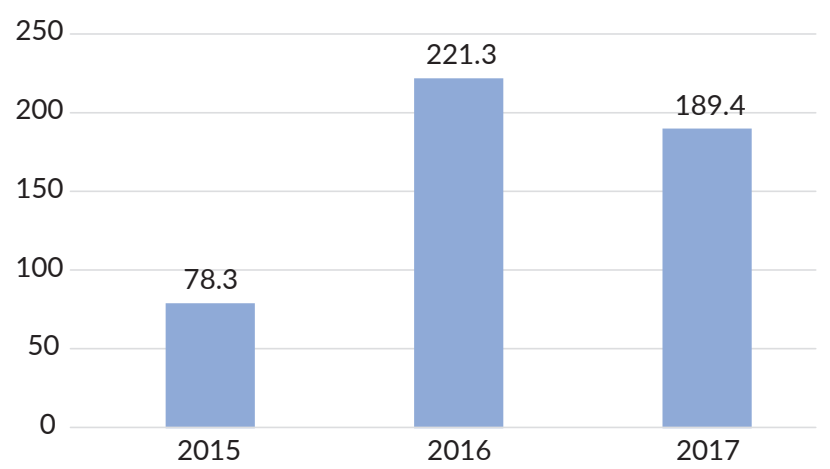

Figure 3. FTE researchers per million (2015-2017).

While not considered a weakness, the Philippines' resident patent applications index at the national and regional office in 2017 lags behind its neighboring countries Singapore (3.1), Malaysia (1.6), Vietnam (1.1), and Thailand (0.9). A similar trend is observed for international patent applications. Along with Vietnam and Indonesia, the Philippines has consistently scored 0 in international patent applications, with other neighboring countries scoring as high as 1.8 per billion GDP.

Table 2. R\&D spending

\begin{tabular}{|c|c|c|c|c|c|}
\hline$R \& D$ Spending & 2013 & 2014 & 2015 & 2016 & 2017 \\
\hline GERD as $\%$ of GDP & 0.1 & 0.1 & 0.1 & 0.1 & 0.1 \\
\hline GERD financed by business as $\%$ of GERD & $62^{*}$ & $56.9^{*}$ & $62^{*}$ & 36.9 & 36.9 \\
\hline GERD financed by foreign investment as $\%$ of GERD & 4.1 & 4.1 & 4.1 & 1.8 & 1.8 \\
\hline
\end{tabular}

\footnotetext{
*Indicates a strength
} 


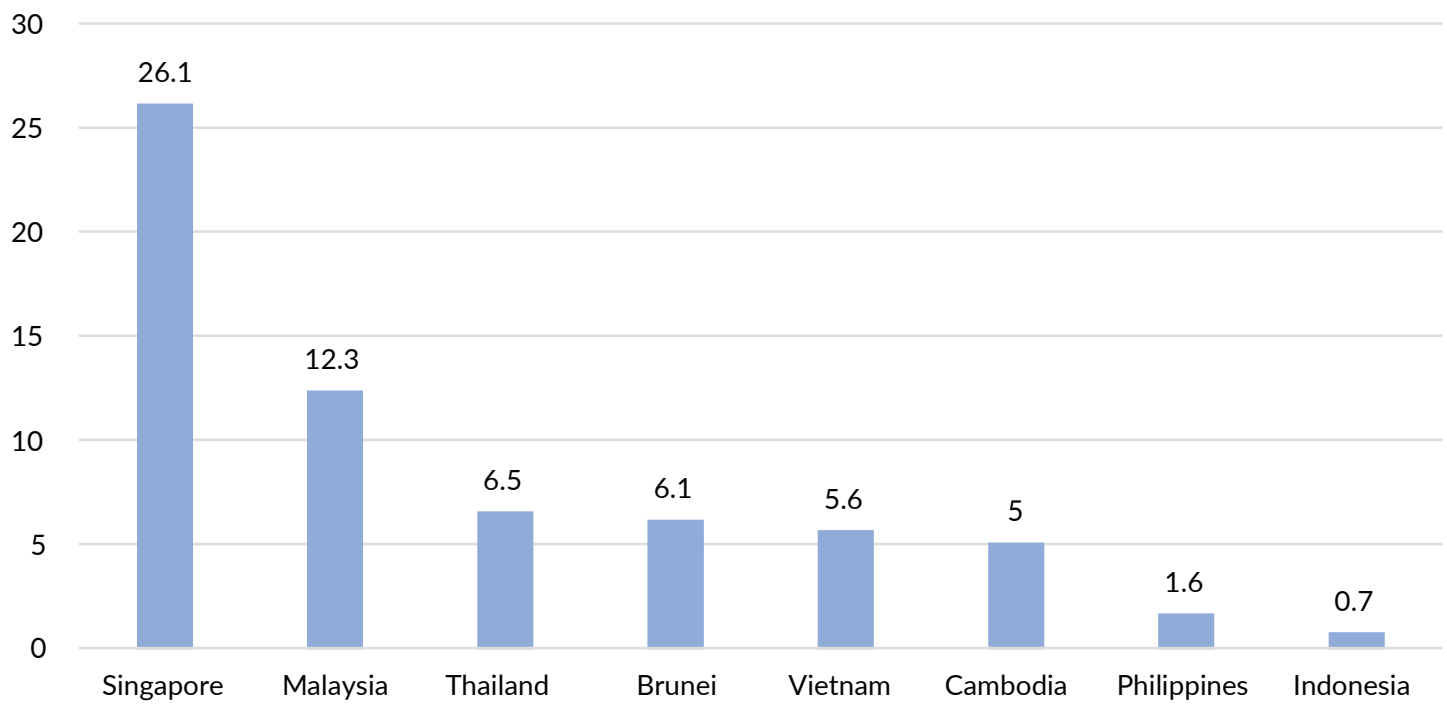

Figure 4. Scientific and Technical Journal Publication per Billion GDP in International Dollar of Selected South East Asian Countries (2017).

The country is considered weak in scientific and technical journal publication and has been declining in performance since 2014 (Table 3). ${ }^{20-24}$ It currently ranks 120th out of 127 countries in journal publication output. A huge gap was observed with neighboring countries, with only Indonesia scoring lower than the Philippines in 2017 (Figure 4).

\section{PRODUCTION SECTOR}

Businesses, firms, farms, and other productive entities generate demand for S\&T for the production of goods and services. ${ }^{8}$ Businesses foster their competitiveness, productivity, and quality by employing qualified individuals as well as adopting innovative business and organizational models. ${ }^{20}$

Table 4 shows $\mathrm{R} \& \mathrm{D}$ activity in the production sector. ${ }^{20-24}$ The country's university-industry research collaboration has been in decline since 2015. Despite this, it currently ranks 59th globally. The country has performed strongly in hiring researchers in the business enterprise since 2016, ranking 8th globally. Almost 65\% of FTE researchers are in business enterprises and are involved in the creation of new knowledge, products, methods, and management of projects. Since 2013, less than $25 \%$ of the country's total workforce were employed in knowledge-intensive jobs. This includes managers, professionals, associate professionals, legislators, senior officials, and technicians.

Figure 5 shows the adoption of new business and organizational models as a result of innovation. Between 2013 and 2015, innovations strongly enabled changes in business and organizational models, ranking within the top 30 globally, indicating that businesses were eager and had the capacity and resources to adopt new innovations.

\section{INFRASTRUCTURE}

In creating an ideal environment for S\&T, countries must recognize the role of adoption and absorption of, and adaptation to existing technologies generated

Table 3. Research Output per Billion GDP in International Dollars (2013-2017)

\begin{tabular}{|c|c|c|c|c|c|}
\hline Per billion GDP in International Dollars & 2013 & 2014 & 2015 & 2016 & 2017 \\
\hline Resident patent applications filed at national or regional office & 0.5 & 0.4 & 0.3 & 0.5 & 0.5 \\
\hline $\begin{array}{l}\text { International patent application filed by residents at the } \\
\text { Patent Cooperation Treaty }\end{array}$ & 0 & 0 & 0.3 & 0 & 0 \\
\hline Scientific \& technical journal articles* & 2.1 & 2.1 & 1.6 & 1.5 & 1.6 \\
\hline
\end{tabular}

${ }^{*}$ Indicates a weakness

Table 4. R\&D in the Production Sector (2013-2017)

\begin{tabular}{llllll}
\hline R\&D in the Production Sector & 2013 & 2014 & 2015 & 2016 & 2017 \\
University-industry research collaboration & 40.9 & 43 & 46.6 & 46.6 & 41.4 \\
Knowledge-intensive employment, \% of workforce & 20.8 & 22.5 & 23.7 & 23.5 & 24 \\
Researchers in business enterprise, \% of FTE researchers & n/a & n/a & n/a & $54.1^{*}$ & $63.2^{*}$ \\
\hline
\end{tabular}

* Indicates a strength 


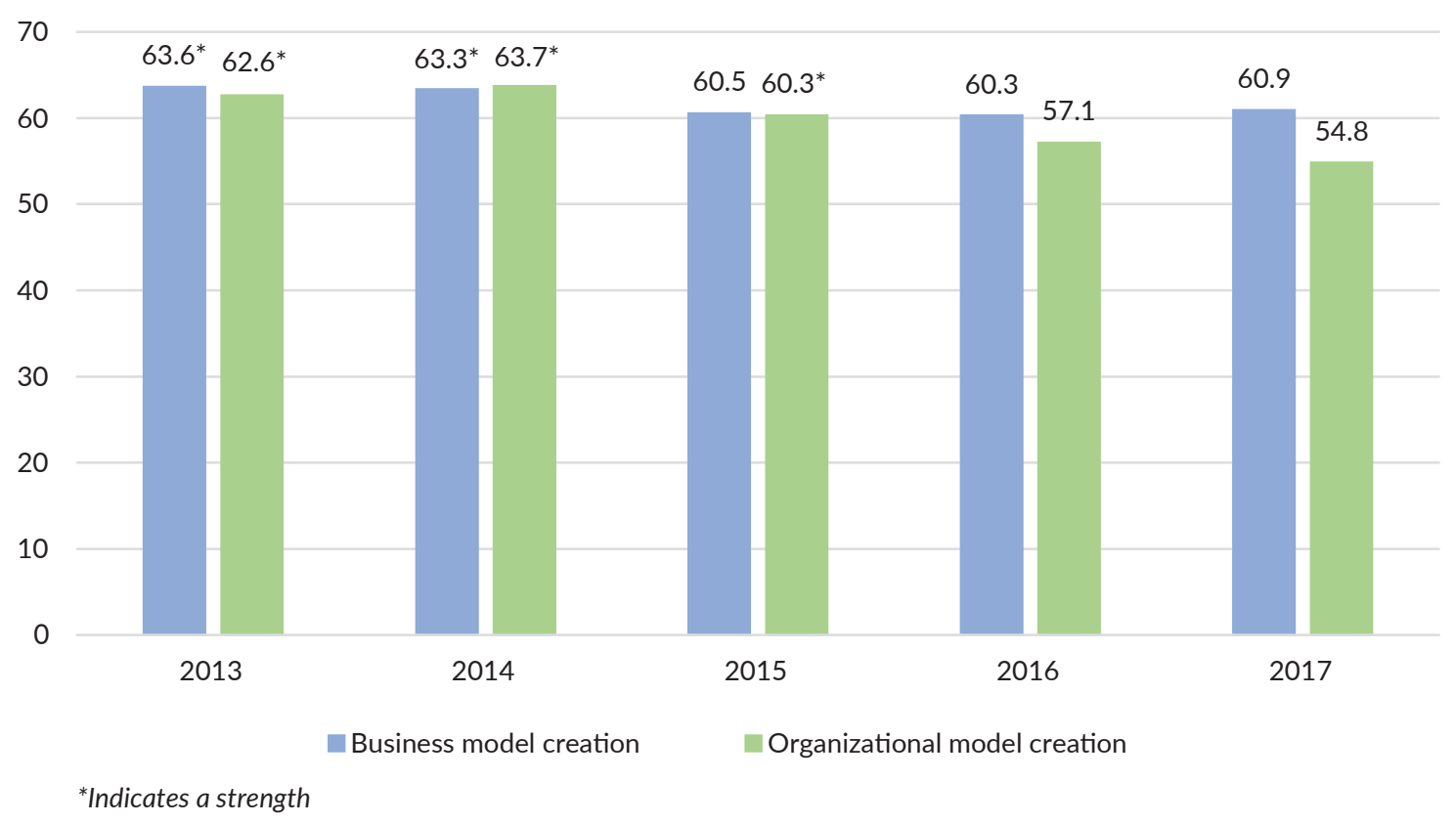

Figure 5. New Business and Organizational Models (2013-2017).

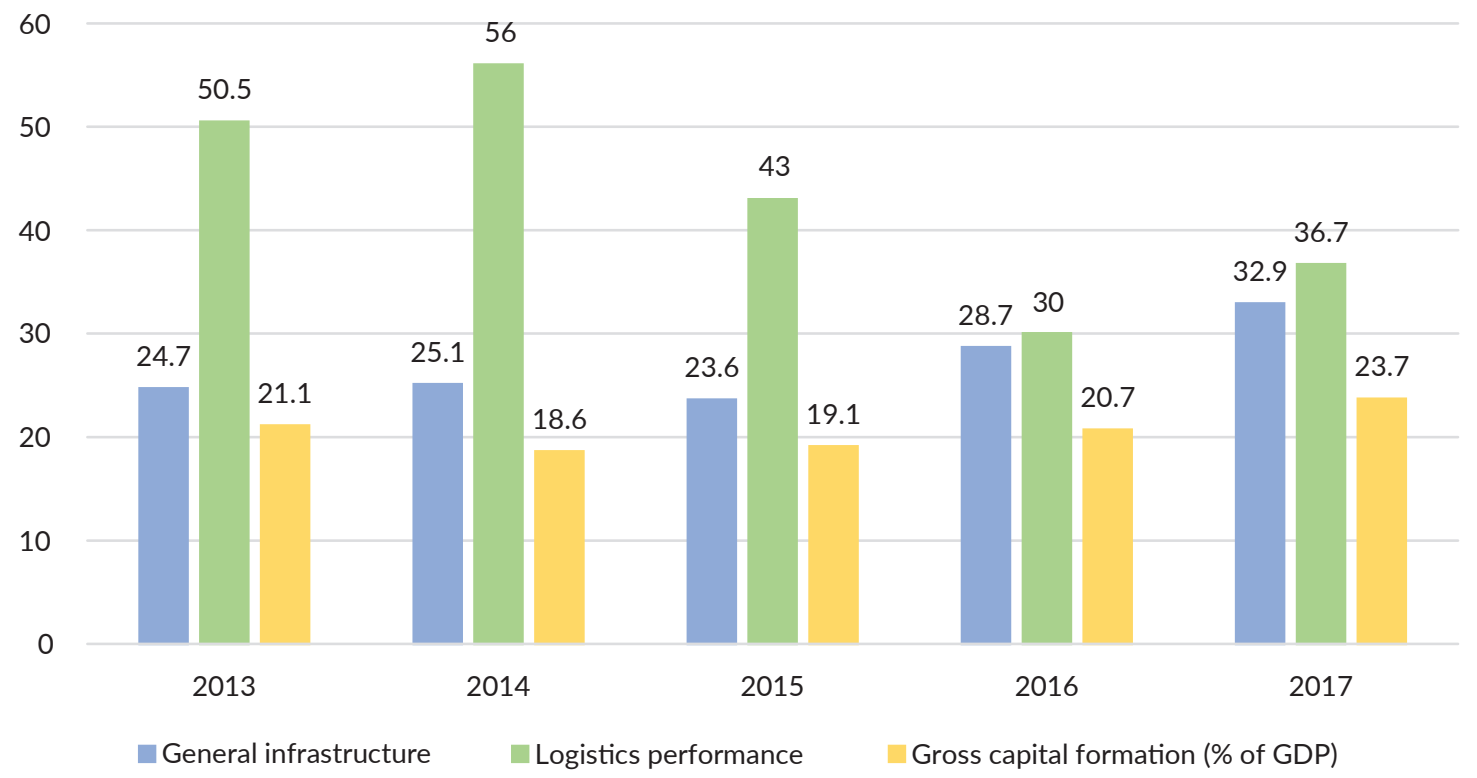

Figure 6. Philippines General Infrastructure Score (2013-2017).

overseas. To catch up with technological advances globally, absorptive capacity must be created in all stakeholders involved in S\&T. This includes not just strengthening human capacity development but also infrastructures. ${ }^{8}$ Strong communication, transport, and energy infrastructures facilitate production and exchange of ideas, services, and goods. It leads to increased efficiency, lower transaction costs, better market access, and sustainable growth. ${ }^{20}$

Figure 6 shows the Philippines' general infrastructure scores from 2013 to 2017. ${ }^{20-24}$ It assesses two major subpillars. First is logistical performance, measured as an index, that takes into consideration multiple dimensions of trade including customs performance, infrastructure quality, and timeliness of shipments. Second is gross capital formation, which includes net inventories of the economy, including 1) land improvement, plant, machinery, and equipment purchases; 2) construction of roads, railways, and other transport infrastructure; and 3) construction of schools, offices, hospitals, residential areas, and commercial or industrial buildings. 
The country's score and global rank for general infrastructure has been increasing since 2013. Disaggregated data show that the country has been devoting increased percentage of its GDP to Gross Capital Formation (GCF). Currently, the country ranks 50th out of 127 countries in GCF as \% of GDP. This is a trend observed in developing countries, where investment in fixed assets is seen to enable rapid economic growth. Conversely, score and global rank in logistics performance has been decreasing. This is indicative of a less efficient customs and border management clearance, decreasing quality of trade and transport infrastructure, decreasing ease in shipping arrangement, decreasing quality of logistics services, and decreasing timeliness of deliveries.

Table 5 shows the Philippines' information and communication technologies (ICT) scores from 20132017..$^{20-24}$ It measures four subpillars: ICT access, ICT use, government's online services, and e-participation. The country's score for overall ICT and for each of its subpillars has been increasing since 2013. It should be noted that the country's global ranking has remained stable despite increasing performance, indicating that global performance as a whole may be on the rise. The country ranks 4th in overall ICT performance compared with neighboring countries.

\section{FINANCIAL SECTOR AND MARKETS}

For innovation to occur, an environment that supports investments and competition is critical for success. Since 2014, the density of newly registered business has remained stagnant (Table 6). This is consistent with institutional scores, which rated the Philippines as weak in policies that ease the process of starting a business. The country currently ranks 59th in intensity of local market competition, with a score of 70.2 in $2017 .{ }^{20-24}$
Table 7 shows the foreign direct investment (FDI) data for the Philippines from 2013 to 2017..$^{20-24}$ FDI inflows have been on a general upward trend since 2013 and were considered strengths from 2016 to 2017, indicating that foreign economies find the country attractive due to factors that may include market potential, skilled workforce, and favorable laws and incentives. Similarly, FDI outflows have been increasing, which may indicate that local businesses may be seeking more favorable investment conditions abroad.

\section{CONCLUSION AND RECOMMENDATIONS}

The involvement of the S\&T sector is indispensable to the achievement of national and international health goals of the Philippines. To further strengthen their role in fulfilling the health research needs of the country, multiple elements in the S\&T environment must be considered: 1) framework considerations or policies, 2) education and research, 3) the production sector, 4) infrastructure, and 5) the financial and market sector.

The Philippines has improved in formulating and implementing policies that create an enabling environment for S\&T. Policies implemented throughout the years in the Philippines have managed to balance strengthening infrastructure capacity while increasing translation and uptake of new knowledge and technologies by enterprises. The country must keep the trend of implementing long term strategies that cater to local needs, realities, and cultures. Its policies should encourage entrepreneurships and ease the establishments of start-ups to create demand for S\&T innovations, increase competition, and attract foreign investments. ${ }^{25}$

Table 5. Philippines ICT Scores (2013-2017)

\begin{tabular}{|c|c|c|c|c|c|}
\hline & 2013 & 2014 & 2015 & 2016 & 2017 \\
\hline ICTs & 28.6 & 29.9 & 42.7 & 46.1 & 50.6 \\
\hline ICT access & 33.2 & 34.1 & 43 & 43.9 & 47 \\
\hline ICT use & 10.5 & 14.6 & 22.8 & 33.5 & 29.3 \\
\hline Government's online service & 49.7 & 49.7 & 48 & 48 & 66.7 \\
\hline E-participation & 21.1 & 21.1 & 56.9 & 56.9 & 59.3 \\
\hline
\end{tabular}

Table 6. New business density and competition (2013-2017)

\begin{tabular}{llllll}
\hline & 2013 & 2014 & 2015 & 2016 & 2017 \\
New business density per thousand population 15-64-year old & 0.2 & 0.3 & $0.3^{*}$ & 0.3 & $0.3^{*}$ \\
Intensity of local competition & 68.2 & 67.8 & 69.2 & 70.4 & 70.2 \\
\hline
\end{tabular}

${ }^{*}$ Indicates a weakness

Table 7. Philippines FDI Data (2013-2017)

\begin{tabular}{llllll} 
FDI & 2013 & 2014 & 2015 & 2016 & 2017 \\
FDI net outflows \% of GDP & 0 & 0.7 & 1.4 & $2.5^{*}$ & $1.9^{*}$ \\
FDI net inflows \% of GDP & $0.8^{a}$ & 1.1 & 1.4 & 2.2 & 1.8 \\
\hline
\end{tabular}

\footnotetext{
* Indicates a strength
}

${ }^{a}$ Indicates a weakness 
The country's S\&T performance has remained largely stagnant despite the availability of human capital. In developing countries, this trend manifests due to issues in quality of science education, weak government-universityindustry linkages, brain drain, and weak S\&T awareness and understanding of the public. ${ }^{26}$ Strategies to counter these issues include the improvement of tertiary education course content to include practical training, strengthening the continuous education program for scientists, and promoting effective interactions of the industry and university sectors through government interventions. ${ }^{27-29}$

The Philippines has devoted low funding to research and development, indicating the low priority that it has for S\&T. This is manifested in the low research output of the country in the form of patents and publications that lags both regionally and globally. The scientific community, its leaders, and the enterprises that benefit from S\&T innovations must present a stronger case for $\mathrm{S} \& \mathrm{~T}$ as an economic stimulus crucial for development.

Increasing government-university-industry links can increase research with commercial potential and value as intellectual property, an entrepreneurial approach to research stemming from the need for national and regional economic development. ${ }^{30}$

University-industry linkages must be further strengthened to develop skills and facilitate the acquisition and adoption of knowledge. Strong R\&D universityindustry linkages can coordinate agendas, avoid duplications, and stimulate investment into the sciences from the business sector. Increased direct interactions between universities and industry is as an indication of a new mode of knowledge production or a changed social contract for science. ${ }^{31}$ Strategies that may stimulate collaboration include R\&D incentives and grants, performance-based funding of public universities, reward systems for researchers, and the development of science parks. $32-35$

The availability of quality infrastructure is a requirement for efficient work of researchers and facilitates adaption of new technologies by enterprises. As research and development becomes increasingly global, it is important to continue the trend of developing fixed assets and improving ICT services. However, these developments must be coupled with good logistical processes to meet the demands of researchers and the industry. ${ }^{36}$

\section{LIMITATIONS AND IMPLICATIONS FOR RESEARCH}

This study is limited by its use of secondary data to assess the S\&T environment of the Philippines. The following recommendations are made for future research:

- Future research into the S\&T environment in the Philippines should assess metrics and indices that would be more applicable in the context of a developing country. This includes S\&T developments which may have improved processes or production but have not necessarily resulted in patent applications or journal publications.

- In-depth research into each element of the S\&T environment can provide insight into the confounding variables that affect the development of the S\&T sector in the country.

\section{Statement of Authorship}

All authors approved the final version submitted.

\section{Author Disclosure}

All authors declared no conflict of interest.

\section{Funding Source}

This paper was funded by the Philippine Council for Health Research and Development.

\section{REFERENCES}

1. Mugabe J. Health Innovation Systems in Developing Countries: Strategies for Building Scientific Technological Capacities. Geneva, Switzerland: WHO; 2005

2. National Research Council. The Fundamental Role of Science and Technology in International Development. Washingon, DC: National Academies Press; 2006.

3. Daar A, Thorsteinsdottir H, Martin D, Smith A, Nast S, Singer P. Top 10 Biotechnologies for Improving Health in developing Countries. Toronto, Canada: Joint Centre for Bioethics; 2002.

4. Olliaro P, Navaratnam V. Technical Cooperative Networks in Developing Countries for Sustainable Access to Affordable, Adapted Medicines. MSF/DND; 2002.

5. Paraje G, Sadana R, Karam G. Increasing international gaps in healthrelated publications. Science. 2005 May 13; 308(5724):959-60.

6. COHRED. The Next Step: An Interim Assessment of ENHR and COHRED. COHRED; 1997.

7. Griffiths P, editor. Strengthening Science and Technology in the Developing World. Sigma Xi Forum and Annual Meeting. Los Angeles, California; 2003.

8. United Nations Conference on Trade and Development. A Framework for Science, Technology and Innovation Polict Reviews. Geneva, Switzerland: UN; 2011.

9. Department of Science and Technology [Internet]. About DOST Manila, Philippines DOST; 2018 [cited 2018 July]. Available from: http://www.dost.gov.ph.

10. Cororaton C. Research and Development and Technology in the Philippines. Manila, Philippines: Philippine Institute for Development Studies, 2003 Contract No.: 10.

11. Republic Act No. 6959. An Act Establishing Provincial Centers for Science and Technology in all Provinces of the Philippines and Appropriating Funds Therefore. July 31, 1990

12. Department of Science and Technology. Science and Technology Agenda for National Development. Manila, Philippines: DOST; 1993.

13. Science and Technology Scholarship Act of 1994; 1994.

14. Inventors and Invention Incentives Act of the Philippines; 1992.

15. An Act Providing a Magna Carta for Scientists, Engineers, Researchers, and Other Science and Technology Personnel in Government; 1997.

16. Republic Act No. 8946. Philippine Science High School (PSHS) System Act of 1997. February 12, 1998.

17. NEDA. Medium-Term Philippine Development Plan 2004-2010. Manila, Philippines: NEDA; 2004.

18. DOST NCR [Internet]. SETUP (Small Enterprise Technology Upgrading Program) Manila, Philippines: DOST NCR; 2018 [cited 2018 July 7]. Available from: http://ncr.dost.gov.ph/index.php/what- 
we-do/technology-transfer/community- empowerment-thru-scienceand-technology.

19. DOST TAPI [Internet]. About TECHNICOM Manila, Philippines: DOST; 2018 [cited 2018 July]. Available from: http://tapitechnicom. dost.gov.ph/.

20. Cornell University, INSEAD, WIPO. Global Innovation Index. Geneva, Switzerland: 2017.

21. Cornell University, INSEAD, WIPO. Global Innovation Index. Geneva, Switzerland: 2013.

22. Cornell University, INSEAD, WIPO. Global Innovation Index. Geneva, Switzerland: 2014.

23. Cornell University, INSEAD, WIPO. Global Innovation Index. Geneva, Switzerland: 2015.

24. Cornell University, INSEAD, WIPO. Global Innovation Index. Geneva, Switzerland: 2016.

25. Lane J. Assessing the impact of science funding. Science. 2009 Jun 5; 324. (5932):1273-5.

26. Azizan S. Strengthening Malaysia's scientific and technological development through human capital development. Procedia Soc Behav Sci. 2013; 91:648-53. doi: 10.1016/j.sbspro.2013.08.465

27. Grand C, Tahlin M, Szulkin R. Education and Inequality in Sweden: A Literature Review. Helsinki, Finland: The Research Institute of the Finnish Economy; 2005.

28. Lanciana-Morandat C, Nohara H. A comparative study of R\&D staff in France and Japan: skill formation, career patterns and organizational creation of knowledge: LEST-CNRS; 2000.
29. Radwan I, Pellegrini G. Knowledge, productivity, and innovation in Nigeria: creating a new economy. Washington, USA: The World Bank; 2010.

30. Powers J. R\&D Funding Sources and University Technology Transfer: What is Stimulating Universities to Be More Entrepreneurial? Research in Higher Education. 2004 Feb; 45(1):1-23.

31. Gulbrandsen M, Smeby J. Industry funding and university professors' research performance. Res Policy. 2005 Aug; 34(6):932-50.

32. Awang A, Hussain M, Malek J. Knowledge transfer and the role of local absorptive capability at science and technology parks. The Learning Organization. 2013 May; 20(4/5):291-307.

33. Ramma Y, Samy M, Gopee A. Creativity and innovation in science and technology: Bridging the gap between secondary and tertiary levels of education. Int J Educ Manag. 2015 Jan; 29(1):2-17.

34. Sompong K, Igel B, Smith H. Strategic alliance motivation for technology commercialization and product development. Manag Res Rev. 2014 May; 37(6):518-37.

35. Frank A, Echeveste M. Knowledge transfer between NPD project teams: A method for the identification of improvement opportunities. Int J Qual Reliab Manag. 2012; 29(3):242-64.

36. World Symposium on Sustainable Development. Capacity Building in Science and Technology. Synthesis Workshop on Science and Technology for Sustainable Development. Mexico City; 2002.
The Acta Medica Philippina is now accepting original scientific papers, review articles and case reports for its upcoming issues. Please follow the format for submission as indicated in the "Instructions to Authors" elsewhere in the journal. All papers received shall be properly acknowledged. For inquiries and submission of proposals, please e-mail us at actamedicaphilippina@yahoo.com 